\title{
THE COMPLEX MOBILITIES OF RURAL VERSUS URBAN YOUTH: MOBILITY INTO AND OUT OF THE PARENTAL HOME AND ONE'S COMMUNITY
}

\section{E. Dianne Looker}

\begin{abstract}
This paper examines the options facing rural versus urban youth as they negotiate the complex mobilities of moving into adulthood. Specifically, it looks at the links between geographic mobility into and out of one's home community, and mobility into and out of the parental home. Qualitative and numeric data from a longitudinal survey of 1200 youth provide insight into these transitions. Leaving the parental home is clearly a process rather than an event, and for many it is subjective and ambiguous. More rural youth than urban expected to leave both their parental home and their community, for education and work, and more in fact did leave, by age 19 and 22. This pattern reflects the often limited educational and work options in rural areas. Many youth returned to the parental home for varying lengths of time; again, more rural than urban youth followed this pattern. Urban youth more often have the option of staying close to home to pursue further education or find a job. The parental home serves as an important safety net for youth, especially those who may have been pushed to leave because of limited options nearby. Having the option of returning home gives youth an additional way of dealing with the challenges of their complex mobilities. The results confirm that the pressures on rural youth as they grapple with the mobilities options available to them are quite different than those on their urban counterparts. Thus, rural youth are more often faced with the complexities inherent in the links between social and spatial mobilities.
\end{abstract}

Keywords: youth, rural, mobility, parental home

Acknowledgements: An earlier version of this paper was presented at a conference, Rural Mobilities: Towards Applied and Transformative Understandings, held on March 9 and 10, 2017 in Puebla, Mexico. The author would like to acknowledge the funding provided by the Social Sciences and Humanities Research Council of Canada, which made this research possible.

E. Dianne Looker $\mathrm{PhD}$ is Professor Emerita at Acadia University and at Mount Saint Vincent University. Mailing address: 2248 White Rock Rd., Wolfville, NS B4P 2R1.

Email: dianne.looker@msvu.ca 
International Journal of Child, Youth and Family Studies (2021) 12(2): 48-64

Youth are mobile. Many move from one geographic area to another, either to pursue educational opportunities or to find employment. As they obtain further education and/or work experience, they are also engaging in a form of social mobility - gaining human capital as well as working towards gaining credentials and income. This is not always a straightforward process. Findlay et al. (2015) pointed out:

,...complex movements include the multiple residential mobilities of students in the early stages stages of entering the labour market, which Sage et al. (2013) have shown to involve multiple temporary relocations between place of study, parental home, and residence close to a new place of employment. (p. 392)

Youth are also moving from childhood to adulthood, albeit at different rates that may or may not correspond to their chronological age. Arnett (2000) describes this transition as one of "emerging adulthood" (see also Bynner, 2005). Further, as Mortelmans et al. (2016) noted, the transition from adolescence to adulthood is "demographically dense" in that it involves a number of transitions, including that of leaving the parental home. This particular transition is one that many, if not most, youth see as critical to gaining "adult status" and thereby becoming independent. Data from the survey described in the current paper show that, at age 28, rural "youth" are much more likely than their urban counterparts to say moving from the parental home is "very important" to claiming adult status.

This paper explores the complex mobilities of rural as compared to urban youth, looking at the relationships between spatial/geographic mobility and mobility in and out of the parental home. These various mobilities differ in a number of ways, one of which is their reversibility. Age is irreversible; all youth age at the same rate, although they lay claim to "adult" status at different ages. One of the times that youth in the current study say they are not treated as an adult, even when they are in their late twenties, is if they are living with their parents at age 28.

Gaining human capital and work experience are resistant to being reversed. One can lose one's knowledge and skills, and work experience can become irrelevant, but in most instances, it is safe to assume that skills and experience gained are kept. In contrast, both geographic mobility and mobility into and out of the parental home are fairly easily reversed, and often are. These two mobilities are often linked. In most cases, youth leaving the home community are simultaneously leaving the parental home, although some, of course, move with their parents to a new locale. Many will stay in the same community, but leave the parental home; others will move from the parental home for varying lengths of time, and then return.

What is more, as I will show below, it is not always clear - to the parent or the youth - when and whether the young person has, in fact, "left" the parental home. For many youth, there is a broad transition period during which they live with their parents for a while and away at other times, without a strong sense of which locale counts as the one where they "live". Indeed, this 
ambiguity created difficulties for Statistics Canada when they were designing a survey for 18- to 20 -year-olds in Canada as a first stage of the Youth in Transitions project, which I advised on. For a certain percentage of households, parents and their 18- to 20-year-old child did not agree on whether the young person was living at home, but was temporarily away at school, or had moved out to attend school, and only returned to the parental home for summer and holiday visits.

It may be better to see mobility out of the parental home as a process rather than a discrete event (Rossignon et al., 2016; Tosi, 2016), even though for some youth it may be a discrete event. In this way, the parental home may be the quintessential example of "in-between-ness" (Sheller \& Urry, 2006, p. 219) for youth. See also Rinallo (2016) for a discussion of young adulthood as an "intermediate" stage. Further, mobility out of the parental home is normative. There is a clear cultural expectation that, once they reach a certain age, youth will leave the parental home and establish themselves as independent adults. The age at which this is expected may vary, but the expectation is there. That expectation for mobility is less definitive for geographic and other forms of mobility that youth may experience.

\section{Methods}

The data to explore these complex mobilities come from a longitudinal study of youth, undertaken by the author, who were surveyed at ages $17(N=1,200), 19(N=1,043), 22(N=985)$ and $28(N=736) .{ }^{1}$ The first phase of the study involved 400 youth in a city in central Canada, 400 in the urban area of an Eastern Canadian province, and 400 from rural and small town areas of that province. Detailed, structured, face-to-face interviews were conducted with these youth. At the same time, structured surveys were given to the parents (or legal guardians ${ }^{2}$ ) of the youth. Lists were obtained from schools and school boards in the sample areas and a random sample of those born in the target year (aged 17, turning 18 at the time of the survey) were contacted. There was an over $80 \%$ response rate from the youth and over $70 \%$ from the parents.

Two years later, when the youth were 19 years of age, they were sent a one-page survey asking: "Which of the following are you doing?" and "Which of the following have you done [since first surveyed]?" Each question was followed by a list of possible responses. Three years later - 5 years from the first data collection - a more detailed, structured questionnaire was sent to all the youth (now 22 years of age) who could be traced. A one-page version was sent to those who did not respond after three requests; 63 young people completed this form themselves, and for an additional 47, the information was obtained from an alternative source, usually a parent. In depth, face-to-face, structured interviews were also undertaken with 483 youth at age 22 , half from rural areas and half from urban areas at the time of the first survey.

\footnotetext{
${ }^{1}$ See Andres et al., (1998) and Looker (2000) for details of the sample design and data collection.

${ }^{2}$ Only $1 \%$ of the youth were living with neither parent but with two legal guardians. Three quarters were living with two parents.
} 
Responses to all the preset questions were coded and linked in a longitudinal numeric file for quantitative analysis. The data set also includes qualitative data from verbatim responses to the many open-ended questions in the surveys (about their definitions of adulthood, and their various moves and why they made them), as well as verbatim responses from the detailed qualitative interviews with the 483 participants at age 22. These verbatim, qualitative answers are linked, via the person's identification number, to the numeric file.

This data set has some limitations. First, the rural sample is drawn entirely from one fairly small, culturally homogeneous province. It does not include any youth attending a school on a First Nation reserve. Considerable time, money, and effort was put into tracing the youth for the follow-up portions of the study. Those investments paid off in terms of strong response rates, and thus minimized non-response bias due to attrition. Nevertheless, those whose paths have been more problematic (from their point of view) may have been less willing to share their details. Those who were less mobile were easier to trace - a reality that is particularly relevant given that the focus of this analysis is on mobility. Despite these limitations, the overall patterns of mobility are very similar to those reported in other jurisdictions and other time frames. What this analysis adds are the voices of the youth as to why they made particular mobility decisions.

The primary focus of the present paper will be on mobility into and out of the parental home, and its links to geographic mobility, for rural and urban youth. Some of the mobility patterns are gendered; gender differences will be highlighted where relevant.

\section{Expectations}

In the first phase of the research, when the youth were 17 years of age, both the youth and their parents were asked if they thought the young person would stay in their current community. The responses of rural residents differed markedly from those of urban residents. ${ }^{3}$

Table 1. Will Youth Stay in Community? Parental Responses when Youth is Age 17

\begin{tabular}{clcccc}
\hline & & \multicolumn{3}{c}{ Mother's response (\%) } & Father's response (\%) \\
\cline { 3 - 6 } Row & Prediction & Rural & Urban & Rural & Urban \\
\hline 1 & Definitely not stay & 13 & 3 & 14 & 2 \\
2 & Probably not stay & 55 & 30 & 54 & 33 \\
3 & Total “will not stay" & 68 & 33 & 68 & 35 \\
\hline 4 & Probably stay & 29 & 59 & 30 & 60 \\
5 & Definitely stay & 3 & 8 & 3 & 6 \\
6 & Total "will stay" & 32 & 67 & 33 & 66 \\
\hline
\end{tabular}

Note. Rural mothers: $n=242$; Urban mothers: $n=551$; Rural fathers: $n=188$; Urban fathers: $n=412$.

\footnotetext{
${ }^{3}$ Throughout this analysis, "rural" and "urban" refer to the locale where the youth lived at age 17, at the time of the first survey. As noted, there was geographic mobility between the time the youth were 17 and the time they were 22 but the details of this mobility are not discussed here. Rather the focus is on those from rural and from urban areas.
} 
As we see in Table 1, two thirds of the parents in urban areas said that they expected their son or daughter to stay in the community (67\% of mothers and $66 \%$ of fathers; Table 1 , row 6 ). In contrast, two thirds of the parents in rural areas $(68 \%$ of mothers, and $68 \%$ of fathers; Table 1 , row 3 ) said that they expected their child to leave the community. The youth were asked if they were likely to stay in their current community. Again, there was an urban-rural split: $58 \%$ of urban youth said "yes", compared to $27 \%$ of rural youth (data not shown). Here we see evidence of the expectation not only of leaving rural areas, but of staying in urban ones. Note that there were no differences in these responses based on the gender of the child.

The 17-year-olds were also asked how important it was to them, "as a person", to stay in their current area. Over half of the urban youth (55\%) said it was important to them, compared to $42 \%$ of rural youth. In contrast, $22 \%$ of rural youth and $10 \%$ of their urban counterparts said it was "not at all important" to stay (detailed data not shown) 4 . Unsurprisingly, the expectation for rural youth leaving is partly based on educational opportunities (Corbett, 2007). However, that is not the whole story. Parents and youth in rural areas were also more likely to agree that, "Young people have a better chance of getting a good job if they leave here" (see Table 2). Only a quarter of urban parents and urban youth agreed with this statement compared to $70 \%$ of rural parents and rural youth (see Table 2, row 3).

Table 2. Agreement with "Young People Have a Better Chance of Getting a Good Job if They Leave Here": Parental and Youth Responses when Youth is Age 17

\begin{tabular}{clcccccc}
\hline & \multicolumn{3}{c}{ Mother's response (\%) } & Father's response (\%) & \multicolumn{2}{c}{ Youth response (\%) } \\
\cline { 2 - 7 } Row & Level of agreement & 43 & 11 & 36 & 10 & 36 & 8 \\
\hline 1 & Strongly agree & 34 & 15 & 36 & 15 & 36 & 17 \\
2 & Agree somewhat & 77 & 26 & 72 & 25 & 72 & 25 \\
3 & Total "agree" & 8 & 21 & 13 & 19 & 16 & 31 \\
\hline 4 & Neither agree nor disagree & 8 & 16 & 7 & 21 & 9 & 28 \\
\hline 5 & Disagree somewhat & 6 & 38 & 8 & 36 & 3 & 16 \\
6 & Strongly disagree & 14 & 54 & 15 & 57 & 21 & 44 \\
7 & Total "disagree" & &
\end{tabular}

Note. Rural mothers: $n=247$; Urban mothers: $n=574$; Rural fathers: $n=192$; Urban fathers: $n=417$; Rural youth: $n=332$; Urban youth: $n=853$.

The expectation at age 17 is that many rural youth will leave both the parental home and their community. The longitudinal nature of the data set allowed us to follow these youth to see whether they did, in fact, leave.

\footnotetext{
${ }^{4}$ This rural-urban difference is the only rural-urban difference evident in the youth's responses to a whole set of questions about what is important to them including: involvement in community activities, earning a lot of money, developing friendships, being physically active, marriage or living together with a partner, having a steady job, involvement in leisure-time activities, involvement in work or career, family relationships, doing well in school, having children, travelling to different places, working to correct social problems, and "owning your own home".
} 
International Journal of Child, Youth and Family Studies (2021) 12(2): 48-64

\section{Mobility Out of the Parental Home and Community}

There was no rural-urban (or gender) difference in the proportion of youth who, at age 17, were still living with their parents or legal guardians. Over $90 \%$ of the youth were still in the "parental" home at that point. That picture had changed by the time of the first follow-up survey, at age 19 . At that point over half (54\%) of the rural youth had left their community, compared with $33 \%$ of urban youth (see Table 3, row 6$)$. Even more rural youth (62\%) had left the parental home, compared to $41 \%$ of urban youth (Table 3 , row 5 ).

Table 3 gives the details of the intersections of these two types of mobilities for rural and urban youth at ages 19 and 22. It is important to note that the measures differ for the two ages. At age 19 , the youth were directly asked if they had moved out of the parental home and if they had moved from their community since the first survey (when they were 17). In other words, this is a subjective report by the youth: to respond "yes" to this question, they would have had to regard themselves as having, at some point, moved out. As we will see below, youth varied in their definitions of what actually constitutes "moving out". More females than males, in both rural and urban areas, had moved out of the parental home by age 19 (data not shown).

At age 22, the youth were asked who, including parents and guardians, lived in their current household; for this analysis, their answers were tabulated into a dichotomy: "living with one or both parents/guardians" or "not". They were also asked the name of the community in which they were currently living (at age 22), which was coded into a dichotomy: "same community" or "different community" (from the one they were living in at the time of the original survey when they were 17). Some could have left the community, or the parental home, and returned; these youth would be grouped with others at age 22 who had never left at all. In other words, the 22year-olds were not asked whether or not they had ever left the parental home.

Table 3. Percentage of Youth Who Left Home Community and/or Parents by Age 19 and Age 22

\begin{tabular}{llrrrr}
\hline & & \multicolumn{2}{c}{ Age 19 } & \multicolumn{2}{c}{ Age 22 } \\
\cline { 2 - 5 } Row Location & Rural (\%) & Urban (\%) & Rural (\%) & Urban (\%) \\
\hline 1 & Not with parent(s) nor in same community as earlier & 51 & 28 & 44 & 16 \\
2 & Not with parent(s) but in same community as earlier & 11 & 13 & 15 & 19 \\
3 & With parents and in same community as earlier & 36 & 55 & 32 & 60 \\
4 & Not in same community as earlier, but with parent(s) & 3 & 5 & 9 & 5 \\
5 & Total left parents (rows 1 + 2) & 62 & 41 & 59 & 35 \\
6 & Total left community (rows 1+4) & 54 & 33 & 53 & 21 \\
\hline
\end{tabular}

Note. Rural age 19: $n=309$; Urban age 19: $n=732$; Rural age 22: $n=239$; Urban age 22: $n=546$.

The results show that similar (small) percentages of rural and urban youth had left the community with their parents (Table 3, row 4), and similar percentages were no longer living with their parents but had not left their community (Table 3, row 2). However, many more rural youth than urban (51\% vs. $28 \%$ at age $19 ; 44 \%$ vs. $16 \%$ at age 22$)$ had left both the community and their parents (Table 3, row 1). Conversely, a higher percentage of urban youth were living at home with 
their parents at age 19 (55\% vs. 36\% of rural youth; Table 3, row 3$)$ and age $22(60 \%$ vs. 32\% of rural youth). In other words, there is, especially for rural youth, a clear link between mobility out of the parental home and mobility out of their "home" community.

Overall, as the summary rows in Table 3 (rows 5 and 6) show, more rural youth had left the parental home at age 19 (62\% vs. 41\% of urban youth), and age 22 (rural: 59\%; urban: 35\%). More rural youth had also left the community in which they had been living at age 17 (54\% vs. 33\% urban at age $19 ; 53 \%$ vs. $21 \%$ urban at age 22 ). This difference in the proportion of rural youth who are mobile is central to the discussion in this paper. The greater mobility of rural youth reflects the often limited range of options available to them compared to urban youth. A clear pattern of gender difference has also been observed (data not shown). More males than females either had never left the parental home, or had left and returned. These gender differences were evident for both rural and urban youth. As of age 22,36\% of rural females were living with one or both parents, compared to $50 \%$ of rural males, $59 \%$ of urban females, and $67 \%$ of urban males.

This intersectionality of types of mobility highlights the dilemma facing rural youth, which Corbett (2007) captured in his insightful analysis in Learning to Leave. If rural young persons want to pursue post-secondary education, especially university, they usually have to leave their home communities and therefore their parents' homes. ${ }^{5}$ Although urban youth may opt to further their education in another locale, university or college attendance is available in virtually all Canadian cities. In other words, for some youth (particularly those in rural areas) the decision to extend one's human capital by pursuing further education means they must make at least a temporary transition out of the parental home and their home community.

\section{The "In-Between" Process of Leaving Home}

The true complexity of the process of leaving the parental home is evident in the words of the survey participants. Some youth who had left to pursue educational options, and had returned during the summers, said they had not really left. For example, one young woman from a rural community said: "There were two stages — one when I went to [university]; the other was after I graduated and moved to [city] — that was the big move out. I think when I was 17 and went to [university] I still considered I lived here." Similarly, a young man from an urban area explained that he came back summer "because it's where I live". An urban female said: "I only went away to attend university - I never considered it moving out". Similarly, another said: "I went to England for university - I couldn't take them with me. It wasn't like I left or moved out" (urban female).

In contrast, many others with exactly the same pattern of living away from home during the school year, and back during summers, felt they had moved out and were "only back for the summers". One rural female commented on how gradual the "moving out" process was. "It started

\footnotetext{
${ }^{5}$ See Frenette $(2003,2007)$ for detailed analyses of the impact of proximity to colleges and universities on the post-
} secondary enrolments of rural youth. 
out just a few days and progressed. I had clothes at home and here [with her boyfriend]. I could spend time with my boyfriend and it was nice and quiet down here. I was in transition for a time, in and out but definitely out by the spring." Another said: "Both: moved back and forth from school and work" (rural female).

So, moving out of the parental home seems to be a subjective matter. Interestingly, some youth were inconsistent from one survey to the next regarding their date of moving out, stating first that they had not moved out by a given date, but later that they had left the parental home before then. In other words, they revise their idea of when they actually moved out. Some reported having moved out, but then clarified that it had been for just a few days or weeks; others who were away for months at a time considered themselves still to be living "at home".

How long does one have to be away to be classified as having "left"? How long must one live with parents again to be counted as being "back"? Some youth classified the return in the summer as "coming home", others as "visiting for the holidays". As Du Bois-Reymond (1998) noted: "According to one's life situation, one moves around between one's own place and the parents' home, and leaving the parents' home is not as final as it used to be."

The complexity of the process is also evident in the fact that some youth left and returned many times, and not just for summers when they were attending a post-secondary institution elsewhere, although that was the most common pattern. By age $22,57 \%$ of rural youth and $34 \%$ of urban said they had left their parents' home and were not currently living there. An additional 16\% of rural youth, and $22 \%$ of their urban counterparts said they had left but later returned (detailed data not shown).

In sum, given that the transition out of the parental home is a process, not an event, the definition of what is happening and when it happens becomes a complex social construction. These unclear definitions are part of what Leccardi (2006) described as, "changes in the construction of young people's biographies in a social context characterized by great uncertainty, acceleration and fragmentation."

The complexity of this construction becomes evident in the next section of the paper, which looks at the reasons the youth gave for leaving the parental home and then returning to it, reasons that demonstrate that they regarded themselves as having moved out, and (for some) that they had returned. As we have seen, whether these "moves" have taken place is subjective and malleable. Tables 1 to 3, above, provide some of the rural-urban context for these moves. It is clear that not only are rural parents and youth more likely to expect that the young person will leave their home community (Table 1), these rural youth, in fact, are much more likely than urban youth to leave their community and therefore also the parental home. This difference in the proportion of youth leaving (and returning to then again leave) the parental home is the key rural-urban difference. In data not shown, it is evident that, on average, rural youth leave the parental home at a younger age than do urban youth. 
International Journal of Child, Youth and Family Studies (2021) 12(2): 48-64

\section{Reasons for Leaving the Parental Home}

The interviews conducted at age $22^{6}$ provided more detail about the complex process of moving out, as youth were asked for their reasons both for leaving and for returning to the parental home. ${ }^{7}$ Their reasons for leaving are presented below; the following section gives their reasons for returning.

Pursue further education: As indicated earlier, the most common reason for leaving home was to pursue further education at an institution in a different community (usually a city). For most rural youth, the decision to move was dictated by the decision to pursue this further education given that there was not a post-secondary institution in their own community: these youth usually felt that "it was too far to commute" (see also Holdsworth, 2009; Malatest \& Associates, 2002). Urban youth also left their homes and communities for schooling, but only because they had chosen a particular institution that was farther away, not for lack of options in their home community. So, the decision process of pursuing further education is different for rural than for urban youth. For rural youth, the decision is whether to go on to post-secondary education; for urban it is where to go. Most rural youth must accept that the decision to continue their education entails leaving not only their parental home but also their home community. For most urban youth, the decision about further education is independent of the decision to leave home. According to the interviews at age $22,30 \%$ of the urban youth and $43 \%$ of the rural youth left the parental home to pursue schooling elsewhere. However, keep in mind that some of the youth who left their community to attend an educational institution did not "feel" that they had "left home".

Find work: It is not just schooling that pulls or pushes youth to leave the parental home. Youth also leave home to find work, work that is typically more readily available in urban than in rural areas. Sixteen percent of rural youth said they left their parents' home for work; only $9 \%$ of urban youth gave this response. However, it is also the case that many youth return home for the summers (or even permanently) for the work available in their home community. Both rural (13\%) and urban $(10 \%)$ youth said they returned home for work.

Be on one's own: Another motivation to move out of the parental home is to be on one's own, to "be independent". Thirty-one percent of rural and $28 \%$ of urban youth mention this search for independence as the rationale for leaving home. As one young rural woman reported, "I had to for my sanity; it was not that bad, but it was time to leave and be on my own." Another, a young man from a rural area commented: "I figured I could do stuff on my own." Or, as a young woman from

\footnotetext{
${ }^{6}$ Interviews were conducted with a subset (483 youth) of the total sample, who at this stage of the research were 22 years of age. Many of those whose questionnaire responses are reported in Table 3 were not part of these additional detailed interviews.

${ }^{7}$ The youth who were interviewed were asked if they were currently living with one or both parents (or legal guardians). If they said yes, they were asked if they had ever moved out, and if so, when and why, and when and why they moved back. Those who said no, that they were not currently living with their parents or guardians, were asked when and why they had left, and when and why they had ever gone back for any length of time.
} 
International Journal of Child, Youth and Family Studies (2021) 12(2): 48-64

an urban region phrased it, "I just wanted to get my own place, see what it was like on my own and everything." Many moved in with a friend or relationship partner, while others left because they were having a child. These youth tended to also say the move provided a type of independence.

Conflicts: A minority (about $7 \%$ of rural and $8 \%$ of urban youth) left home because of conflicts with their parents or another family member. A rural female commented, "I had problems at home. That's why I quit school and left home." Another rural female commented that she "hated living at home and the restrictions". Some chafed at the rules set by parents: "I was 17 and I had to be home by 10 p.m. and all my friends could stay out until 12 or 1 on school nights. I couldn't do what I wanted; it wasn't fair" (rural female); "I had a dispute with my father; I couldn't take his controlling influence any more" (rural male); "Mom and I were getting on each other's nerves. I thought it was time to be on my own" (urban male).

Involuntary: In a few cases the youth didn't leave, the parents left - to another part of Canada, to an "old folks' home" (grandparents were the guardians in this case) or a lone parent died. Some youth were kicked out: One rural female said, "They [her parents] asked me to [leave]. I never had a job and they were getting on my case, so I left and moved in with an aunt." An urban female commented, "I was pregnant; my parents thought it would be too much of a hassle to have a baby there." One urban woman had to move from her parents' home because she was enrolled for social assistance and "wasn't allowed to live with parents".

\section{Reasons for Moving Back}

As noted above, in the interviews conducted when the youth were 22 years of age, the participants were also asked whether or not they had moved back home and the reasons for this choice. Of course, their comments about returning have to be understood in light of the considerable variation in their definitions of what constituted having "left".

A small number of these youth said they would never go back, but most did - at least temporarily for holidays and weekends, if not summers. Others returned to the parental home for more extended stays. And, of course, at age 22 there were still a number $(60 \%$ of urban, $32 \%$ of rural) who said they had never left (Table 3, row 3).

Fallback option: For many returning youth, the parental home was a fallback option. The parental home as a fallback is part of the parental safety net, as described by other researchers (e.g., Sage et al., 2013; Swartz et al., 2011). If things didn't work out elsewhere, if they couldn't get a job, if their marriage or relationship was in trouble, they moved back "home". Of youth who left home and then returned, $26 \%$ of rural youth and $16 \%$ of urban youth gave reliance on the fallback of parental support as the reason for their return. An additional $9 \%$ to $10 \%$ of rural and urban youth talked about how living at home was cheaper, and thus saved them money. 
International Journal of Child, Youth and Family Studies (2021) 12(2): 48-64

The following quotations illustrate these patterns: "I was finished school and I didn't know what I was doing" (urban male); "I couldn't afford my own place any more" (urban male); “Because I wasn't getting anywhere with my life at that time. I had no job, no education, and I realized I had to get back on my feet..." (urban female); "I ran out of money and had to come home" (rural male); "When [boyfriend] and myself broke up, because of financial reasons I lived at home" (rural female); "I returned home between jobs whenever I had no place to live" (rural female); "To get a job and it was cheap to live here" (rural female).

Opportunities in the community: Others (10\% of urban and $13 \%$ of rural youth) had opportunities in the community where their parents lived for summer or more permanent work. Some found work in their parent's business; others felt they had options because of the contacts they had in the community.

Offer support: While some returned home to get assistance, others came to offer support when needed - a family member was sick, a relative needed a babysitter, or someone close to them needed care.

However, such transitions were not always straightforward. One urban female said, "Coming home people expect things of you. It's harder to come back this time."

\section{Home}

In many of the quotations, whether they were talking about leaving or returning, the youth used the term "home" to describe living with their parents. This terminology raises the question of when a young person can be said to have established a "home" of their own and thus when the parental abode is no longer considered "home". Many of these young people had lived on their own — in academic residences, in apartments, with friends, roommates, siblings, spouses, and partners. Yet, they still referred to their parents' house as "home". For rural youth in particular, the fact that, in most instances, their parents still lived in what they called their "home community" reinforced this definition of home being where their parents are.

\section{Options}

Besides the fluidity of the transitions in and out of the parental home, an underlying dynamic seems to be one of options - options available or restricted to which youth have access. Youth, as emerging adults, "not only vary in the degree of exploration they choose to pursue, but also ... this exploration is not equally available to all young people" (Mortelmans et al., 2016, p. 82). For many rural youth, educational and work options are restricted. Table 2, above, documents that rural youth and parents were aware of the restricted work options available locally even while the young person was still at home. Urban youth can pursue a range of post-secondary and employment options while staying in their home communities, and the results, reported above, suggest that they take advantage of this possibility. 
International Journal of Child, Youth and Family Studies (2021) 12(2): 48-64

The key "option" being explored here is that of staying in the parental home, and of returning once one has left. About a third of both rural and urban young people who said they had left their parents' home also (as of age 22) said they had not returned. For some, this was because they had moved on and established their own home with a partner, and/or child. A minority had left after experiencing conflicts at home; for them, returning was not seen as a viable option. For others, especially those in rural areas, the option of living in or returning to the parental home was not available to those who wanted to pursue certain other options with respect to education, work, or relationships.

\section{Overview of Interview Results}

The tables, below, give a numeric summary of the patterns in these quotes from the interviews with the youth at age 22 . It is important to remember that they were only asked why they left the parental home, and when and whether they returned to the parental home if they reported they had, in fact, at some point left and returned. They were only asked why they returned home if they reported they had, in fact, left. As the quotations have shown, the youths' views about whether they had left and whether they had returned were fluid and ambiguous. With that caveat in mind, Table 4 and Table 5 allow for a more systematic comparison of the responses given by the 22year-old youth (who are designated "rural" or "urban" according to where they were living at age 17). The number of observations differs between the two tables because only those who said they had left the parental home at some point were asked if they had returned, and, if so, why they had returned. Also, individual participants often advanced more than one reason for leaving or returning, and so were counted in multiple rows. Not all reasons for leaving or returning are listed: for example, a handful said they had left to travel, and a few had left home or returned home because they were pregnant.

Table 4. Reasons for Leaving the Parental Home: From Interviews, Age 22

\begin{tabular}{clcc}
\hline & Selected reasons for leaving & Rural (\%) & Urban (\%) \\
Row & the parental home & 43 & 30 \\
2 & Schooling & 16 & 9 \\
2 & Work & 31 & 28 \\
3 & Independence/living with another & 5 & 8 \\
4 & Conflict at home & 5 & \\
\hline
\end{tabular}

Note. Some individuals gave more than one reason for leaving. This table presents the reasons most frequently given by those who had left. Rural: $n=191$; Urban: $n=144$.

Table 4 documents, from the qualitative interview data, what numeric analyses from other studies (e.g., Looker, 2002; Malatest \& Associates, 2002) have shown: many youth report that they leave home for schooling and for work. Schooling looms large as a source of the rural-urban difference in the likelihood of leaving home. At age 22, more rural than urban (43\% vs. 30\%) participants said they had left home to pursue schooling. For work, the rural-urban difference is also present, but less pronounced: $16 \%$ of rural youth and $9 \%$ of urban youth gave this reason for 
leaving the parental home. It is notable that a relatively high percentage (about 30\%) of both rural and urban youth said they had left to establish some independence.

Table 5 provides a summary of the reasons the 22-year-old youth gave for returning to the parental home once they had left. Rural youth were more likely than urban to mention that they just returned for summers, or just for visits and/or vacations. More importantly, they were more likely than urban youth to give reasons for returning that reflected reliance on the parental home as a safety net ( $26 \%$ of rural vs. $16 \%$ of urban youth were in this category).

Table 5. Reasons for Returning to the Parental Home: From Interviews, Age 22

\begin{tabular}{clcc}
\hline & Selected reasons for returning & & \\
Row & to the parental home & Rural (\%) & Urban (\%) \\
\hline 1 & Schooling & 3 & 3 \\
2 & Work & 13 & 10 \\
3 & To help & 4 & 1 \\
4 & Financial reasons & 10 & 9 \\
5 & Summers only & 25 & 13 \\
6 & Just to visit/vacations & 19 & 2 \\
7 & Fallback/safety net & 26 & 16 \\
\hline
\end{tabular}

Note. Some individuals gave more than one reason for returning to the parental home. This table presents the reasons most frequently given by those who had left and returned. Rural: $n=144$; Urban: $n=83$.

It is not difficult to understand the key rural-urban difference in the rationales for leaving the parental home. Rural youth left to find educational and work options that were generally unavailable in their home communities. When it comes to returning to the parental home, however, what are we to make of the rural-urban differences in rationale? Many more rural than urban youth, of those who had reported leaving (Table 3, row 6), returned for summers and for visits (Table 5, row 6). We know that more of them left (see Table 3). However, these percentages are based on those who say they had left. Moreover, why did more rural than urban youth use their parents as a fallback or safety net (Table 5, row 7)? One interpretation might be that the rural youth left earlier than their urban counterparts, and in greater numbers, because of the limited educational and occupational options they face. Given this "compelled" mobility, these youth may not yet have been as ready as they would have liked for this independence. Of course, those urban youth who were still, or again, living with their parents at age 22 might also have been dependent on the parental "safety net" - they just did not leave home to invoke it. Given the patterns observed for urban youth, and given the limited evidence we have on shifts in mobility patterns when educational options in rural areas are expanded (Frenette, 2003, 2007), it might be safe to assume that many of these rural youth would have opted to stay closer to home if they had had the chance. In other words, not only is the process of leaving home a complex and fluid one, the pressures facing rural and urban youth to leave (and to return) are quite different. 
International Journal of Child, Youth and Family Studies (2021) 12(2): 48-64

\section{Conclusion}

The majority of rural youth and rural parents say they expect that the youth will leave their home community (and therefore the parental home), for education, work, both, or some other purpose. These expectations are largely borne out in this longitudinal study. However, there is considerable "back and forth" mobility as rural youth go through the process of leaving the parental home and community.

Pursuing educational opportunities is a prime driver of migration from rural communities (Corbett, 2007), as this study confirms. Employment is a distant second. In our study, "independence" was a motivation for about a third of the youth; of course, taking on a job or pursuing educational options may also involve establishing some independence from parents. However, for most youth, that independence is apparently explored with the confidence that the parental safety net is there if things do not work out. For many of the young people in this study, their first forays into independent life were short-lived, ending when relationships failed or money ran out.

It is clear from the evidence, presented above, that leaving the parental home is a "process" and a complex and a subjective process at that. Youth, their parents, and a neutral academic observer might each reach different conclusions, based on the same observed "facts", about when and whether a young person had left the parental home, and whether they had returned. Indeed, for some, it may be that "home" is as much or more a subjective emotional attachment to a locale rather than a specific place of residence.

This analysis has documented some of the complexities of the process of moving into and out of the parental home. This transition is expected of youth at some point - it is, as noted at the start of the paper, a normative type of mobility. The timing is variable, however, and dependent in part on whether the parents live in a rural or an urban community.

Youth from rural areas more often felt compelled to link geographic mobility with mobility into and out of the parental home. This link was necessitated by the relative dearth of educational options in most rural communities. It is exacerbated by a lack of desirable work options as well. However, their home communities seem to have provided temporary summer jobs for at least as many if not more rural as urban youth, insofar as somewhat more rural than urban youth say they return to their home community for work. Urban youth can, of course, stay at home and access the educational and work options there.

We have seen that definitions of whether or not one has, in fact, "moved out" used by youth and their parents were fluid, ambiguous, and sometimes inconsistent. Since more rural than urban youth left their home communities between the ages of 17 and 22, more of them had to confront this ambiguity. Urban youth who lived at home while attending post-secondary education had no difficulty in affirming that they were still living at home. It was those who had gone away who had to address the question of whether they had really left and, if so, when. Were they living at 
International Journal of Child, Youth and Family Studies (2021) 12(2): 48-64

home while temporarily away, or were they living elsewhere and temporarily home when school was not in session? These two interpretations are quite different social constructions of the same complex reality. It is rural youth in particular who have to grapple with these social constructions. Thus, it is rural youth in particular who are faced with the complexities of the link between these spatial and social mobilities. 
International Journal of Child, Youth and Family Studies (2021) 12(2): 48-64

\section{References}

Andres, L., Anisef, P., Krahn, E. D. Looker, \& V. Thiessen. (1998). Longitudinal research on youth transitions in English Canada, from the1970s to the 1990s. In M. Gauthier \& D. Pacom (Eds.), Spotlight on ... Canadian youth research (pp. 21-40). Laval University Press.

Arnett, J. J. (2000). Emerging adulthood: A theory of development from the late teens through the twenties. American Psychologist, 55(5), 469-480. doi:10.1037/0003-066X.55.5.469

Bynner, J. (2005). Rethinking the youth phase of the life-course: The case for emerging adulthood? Journal of Youth Studies, 8(4), 367-384. doi:10.1080/13676260500431628

Corbett, M. (2007). Learning to leave: The irony of schooling in a coastal community. Fernwood Press.

Du Bois-Reymond, M. (1998). “I don't want to commit myself yet”: Young people's life concepts. Journal of Youth Studies, 1(1), 63-79. doi:10.1080/13676261.1998.10592995

Findlay, A., McCollum, D., Coulter, R., \& Gayle, V. (2015). New mobilities across the life course: A framework for analysing demographically linked drivers of migration. Population, Space and Place, 21(4), 390-402. doi:10.1002/psp.1956

Frenette, M., (2003). Access to college and university: Does distance matter (Catalogue no. 11F0019MIE - No. 201). Statistics Canada, Analytical Studies Branch. https://citeseerx.ist.psu.edu/viewdoc/download?doi=10.1.1.200.8051\&rep=rep1\&type=pdf

Frenette, M. (2007). Do universities benefit local youth? Evidence from university and college participation, and graduate earnings following the creation of a new university (Catalogue no. 11F0019MIE — No. 283). Statistics Canada. https://www150.statcan.gc.ca/n1/en/catalogue/11F0019M2006283

Holdsworth, C. (2009). 'Going away to uni': Mobility, modernity, and independence of English higher education students. Environment and Planning A: Economy and Space, 41(8), 18491864. doi:10.1068/a41177

Leccardi, C. (2006). Facing uncertainty, temporarilities and biographies in the new century. In C. Leccardi \& E. Ruspini (Eds.), A new youth?: Young people, generations and family life (pp. 15-40). Routledge, Taylor \& Francis.

Looker, E. D. (2000, June). Leaving the parental home: Implications for rural and urban youth [Paper presentation]. Annual meeting of the Canadian Sociology and Anthropology Association, Edmonton, Alberta, Canada. 
International Journal of Child, Youth and Family Studies (2021) 12(2): 48-64

Looker, E. D. (2002). Why don't they go on? Factors affecting the decisions of Canadian youth not to pursue post-secondary education. Canada Millennium Scholarship Foundation. https://qspace.library.queensu.ca/bitstream/handle/1974/5811/looker_en.pdf?sequence=1\&isA llowed $=\mathrm{y}$

Malatest, R. A., \& Associates. (2002). Research into rural youth migration. Rural Secretariat. https://youthrex.com/wp-content/uploads/2019/02/A22-272-2002E.pdf

Mortelmans, D., Meier, P., \& Defever, C. (2016). Intersectionality in young adults' households: A quantitative perspective. In D. Mortelmans, K. Matthijs, E. Alofs, \& B. Segaert (Eds.), Changing family dynamics and demographic evolution: The family kaleidoscope (Ch. 4). Edward Elgar.

Rinallo, J. (2016, July 10-14). Is time to leave the nest? Describing and explaining time in the transition from youth to adulthood [Paper presentation]. 3rd ISA Forum of Sociology, Vienna, Austria. https://www.isa-sociology.org/uploads/files/isa2016 forum abstract book.pdf

Rossignon, F., Studer, M., Gauthier, J.-A., \& Le Goff, J.-M. (2016). Childhood family structure and home-leaving: A combination of survival and sequence analyses. In G. Ritschard \& M. Studer (Eds.), Proceedings of the international conference on sequence analysis and related methods: LaCOSA II (pp. 383-427). https://acosa.lives-nccr.ch/sites/lacosa.livesnccr.ch/files/proc-lacosa2-rossignonstudergauthierlegoff paper 11.pdf

Sheller, M., \& Urry, J. (2006). The new mobilities paradigm. Environment and Planning A: Economy and Space, 38(2), 207-226. doi:10.1068/a37268

Sage, J., Evandrou, M., \& Falkingham, J. (2013). Onwards or homewards? Complex graduate migration pathways, well-being, and the 'parental safety net'. Population, Space and Place, 19(6), 738-755. doi:10.1002/psp.1793

Swartz, T. T., Kim, M., Uno, M., Mortimer, J., \& O’Brien, K. B. (2011). Safety nets and scaffolds: Parental support in the transition to adulthood. Journal of Marriage and Family, 73(2), 414-429. doi:10.1111/j.1741-3737.2010.00815.x

Tosi, M. (2016). Leaving home sooner or later: Co-residence and parent-adult child relations in Italy and Sweden [Doctoral dissertation, University of Trento]. http://eprintsphd.biblio.unitn.it/1748/ 